\title{
Communication
}

\section{A Shape-Persistent Polyphenylene Spoked Wheel}

\author{
Yi Liu, Akimitsu Narita, Joan Teyssandier, Manfred Wagner, \\ Steven De Feyter, Xinliang Feng, and Klaus Müllen
}

J. Am. Chem. Soc., Just Accepted Manuscript • DOI: 10.1021/jacs.6b10369 • Publication Date (Web): 16 Nov 2016

Downloaded from http://pubs.acs.org on November 17, 2016

\section{Just Accepted}

"Just Accepted" manuscripts have been peer-reviewed and accepted for publication. They are posted online prior to technical editing, formatting for publication and author proofing. The American Chemical Society provides "Just Accepted" as a free service to the research community to expedite the dissemination of scientific material as soon as possible after acceptance. "Just Accepted" manuscripts appear in full in PDF format accompanied by an HTML abstract. "Just Accepted" manuscripts have been fully peer reviewed, but should not be considered the official version of record. They are accessible to all readers and citable by the Digital Object Identifier (DOI®). "Just Accepted" is an optional service offered to authors. Therefore, the "Just Accepted" Web site may not include all articles that will be published in the journal. After a manuscript is technically edited and formatted, it will be removed from the "Just Accepted" Web site and published as an ASAP article. Note that technical editing may introduce minor changes to the manuscript text and/or graphics which could affect content, and all legal disclaimers and ethical guidelines that apply to the journal pertain. ACS cannot be held responsible for errors or consequences arising from the use of information contained in these "Just Accepted" manuscripts. 
Two-dimensional (2D) carbon-based materials have attracted enormous interest in recent decades due to their unique structures, intriguing properties, and versatile applications ${ }^{1-4}$ especially after the landmark advent of graphene. ${ }^{5}$ With the combination of sp-, $\mathrm{sp}^{2}$-, and $\mathrm{sp}^{3}$-hybridized carbon atoms, a number of $2 \mathrm{D}$ carbon materials with different architectures have also been synthesized and/or theoretically predicted. ${ }^{2,6-18}$ In particular, graphene has attracted major attention during the last decade, which also stimulated the studies of other 2D carbon materials such as $\gamma$-graphyne and graphdiyne (Figure 1). ${ }^{10,11,14,19,20}$ Atomically precise syntheses of $\gamma$-graphyne and graphdiyne remain elusive, but widely studied phenylene-ethynylene-based macrocycles can be regarded as their molecular subunits. ${ }^{21-25}$

The electronic properties of 2D carbon materials are critically dependent on the composition and arrangement of the sp-, and $\mathrm{sp}^{2}$-, and/or $\mathrm{sp}^{3}$-hybridized carbon atoms. For example, while graphene is a zero-bandgap semimetal, $\gamma$-graphyne and graphdiyne are both predicted to be semiconductors with open bandgaps. $^{12}$ Moreover, theoretical studies elucidate that graphdiyne has an excellent intrinsic electron mobility reaching $10^{5} \mathrm{~cm}^{2} / \mathrm{Vs}{ }^{12}$ Further exploration of the structural diversity of $2 \mathrm{D}$ carbon architecture is expected to furnish materials with unique and tunable properties. Nevertheless, the number of reported examples of 2D carbon materials is still limited. ${ }^{2,6-18}$

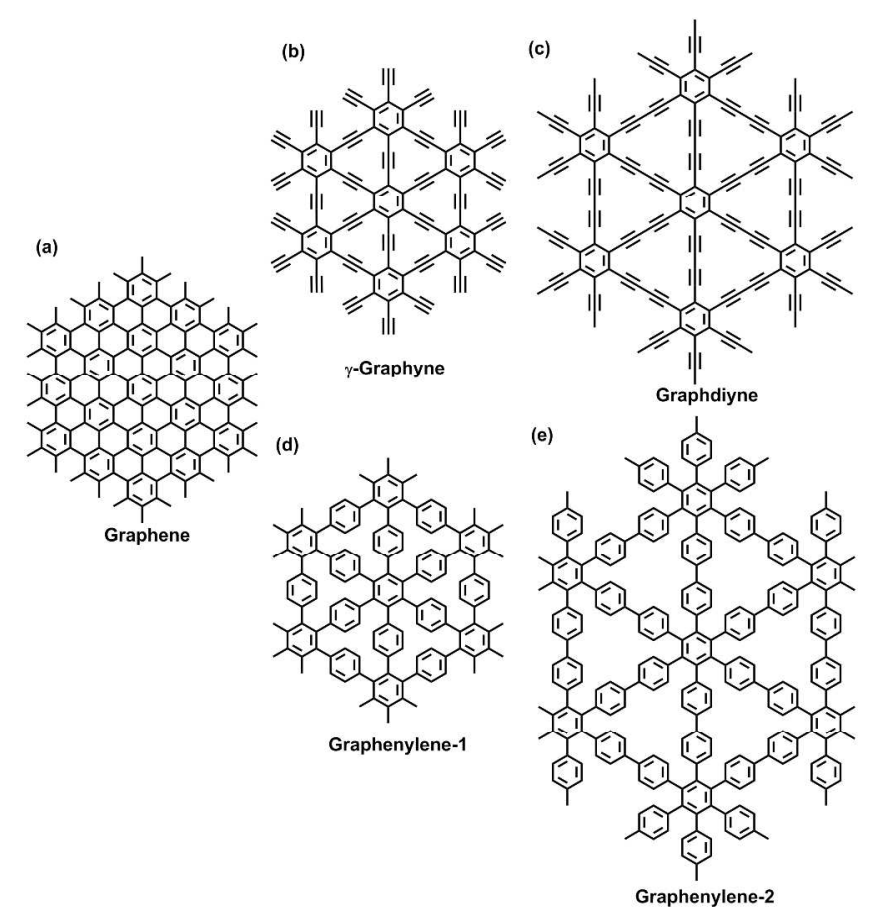

Figure 1. Structural representations of 2D carbon materials: (a) graphene, (b) $\gamma$-graphyne, (c) graphdiyne, and two newly proposed, purely sp ${ }^{2}$-hybridized structures (d) graphenylene-1 and (e) graphenylene- 2 .

By replacing ethynylene groups of $\gamma$-graphyne and graphdiyne with $p$-phenylene units, two purely $\mathrm{sp}^{2}$-hybridized $2 \mathrm{D}$ carbon structures with hexagonal symmetry can be conceived, which we name graphenylene-1 and graphenylene-2, respectively (Figure 1). Notably, graphenylene-1 corresponds to a single-layer substructure of the hypothetical carbon allotrope "cubic graphite", ${ }^{26}$ the synthesis of which still remains elusive. Because the direct and precise fabrication of these 2D carbon architectures is also highly challenging, we start with the synthesis of their subunits with defined sizes and shapes. During the last decade, Höger et al. have developed elegant modular syntheses of large and shapepersistent "molecular spoked wheels", consisting of phenyleneethynylene units, with the diameter reaching $\sim 12 \mathrm{~nm} .{ }^{27,28}$ Adapting their modular protocol, we designed synthetic routes towards two polyphenylene spoked wheels $\mathbf{1}$ and $\mathbf{2}$, consisting of 22 and 37 benzene rings, as nanosized subunits of graphenylene- 1 and 
graphenylene-2, respectively (Scheme 1). Although the preparation of 1 turned out to be elusive by the current method due to the high steric hindrance in the final ring-forming step, 2 could be obtained and unambiguously characterized by NMR, mass spectrometry, and scanning tunneling microscopy (STM). Compound 2 has a $D_{6 \mathrm{~h}}$-symmetrical structure and is expected to be highly shape-persistent with its rigid polyphenylene backbone.

Towards the synthesis of $\mathbf{1}$ and $\mathbf{2}$, dendritic polyphenylene precursors $\mathbf{8 a}$ and $\mathbf{b}$, respectively, are designed with twelve bromo groups at appropriate positions for forming the rims of the wheellike molecules by six-fold aryl-aryl coupling reactions. The hexaphenylbenzene core is expected to serve as a shape-persistent template that facilitates the ring closure. Precursors 8a and $\mathbf{b}$ can be synthesized through the cobalt-catalyzed cyclotrimerization of corresponding alkynes $7 \mathbf{a}$ and $\mathbf{b}$, respectively. On the one hand, 8a with $C_{3}$ symmetry will be inevitably mixed with its undesired, constitutional isomer 8a' (Scheme 1). We therefore introduce strongly polar benzoate groups at the peripheral phenyl rings of precursor 8a to enable its isolation by column chromatography. On the other hand, $\mathbf{8 b}$ with $C_{6}$ symmetry can be obtained as a single isomer and does not require polar groups for the isolation.

Dendritic polyphenylene precursor 8a was prepared over four steps as shown in Scheme 1, and could be easily separated from its undesired regioisomer 8a' through silica gel column chromatography. Matrix-assisted laser ionization time-of-flight (MALDITOF) mass spectrometry (MS) and ${ }^{1} \mathrm{H}$ NMR with $\mathrm{H}-\mathrm{H}$ 2D COSY and nuclear Overhauser enhancement spectroscopy (NOESY) validated the chemical identity of $\mathbf{8 a}$ (see the Supporting Information). The Yamamoto coupling of precursor 8a was then attempted under various conditions, including the use of a microwave reactor (see Table S1), but failed to give the desired compound $\mathbf{1}$, which is most probably due to steric hindrance of the ortho-bromo-biphenyl unit of $\mathbf{8 a}$.

In order to circumvent the steric problem in the last cyclization step, compound $\mathbf{2}$ was next targeted, replacing the phenylene bridges of 1 with biphenylylene units. The synthesis of $\mathbf{2}$ was performed as shown in Scheme 1, following a similar strategy as the one towards $\mathbf{1}$. Suzuki coupling of freshly prepared 9-dodecyl9-borabicyclo(3.3.1)nonane with 4-bromobenzaldehyde gave 4dodecylbenzaldehyde (3b), which was then subjected to Lewis acid-catalyzed condensation with 4-bromoacetophenone to yield triphenylpyrilium salt $\mathbf{4 b}$. Condensation of $\mathbf{4 b}$ with sodium 4iodophenacetate in refluxing acetic anhydride provided oligophenylene $\mathbf{5 b}$, and then Suzuki coupling between $\mathbf{5 b}$ and 1,2bis(4-(4,4,5,5-tetramethyl-1,3,2-dioxaborolan-2-

yl)phenyl)acetylene furnished alkyne $7 \mathbf{b}$. The dendritic precursor $\mathbf{8 b}$ was obtained by the cobalt-catalyzed cyclotrimerization of $\mathbf{7 b}$ in refluxing toluene (Scheme 1). MALDI-TOF MS and ${ }^{1} \mathrm{H}$ NMR analyses proved the chemical identity of precursor $\mathbf{8 b}$ (Figure S28, and S29).

In contrast to the unsuccessful synthesis of $\mathbf{1}$, the intramolecular ring closure of precursor $\mathbf{8 b}$ to compound $\mathbf{2}$ could be efficiently achieved by nickel-catalyzed coupling under microwave treatment. This was most probably due to the reduced steric hindrance and the absence of the $o$-bromobiphenyl moiety in precursor $\mathbf{8 b}$, in comparison to the more congested precursor 8a. Preparative gel permeation chromatography (GPC) allowed for the complete purification, providing $\mathbf{2}$ in $56 \%$ yield as a colorless solid. The MALDI-TOF MS spectrum of $\mathbf{2}$ indicated the presence of a single species with $m / z=3815.5$, consistent with the desired molecular weight of $3815.4 \mathrm{~g} / \mathrm{mol}$, and the experimental isotopic distribution was in perfect agreement with the simulated pattern (Figure 2).
Scheme 1. Synthetic route towards compounds 1 and $2 .^{a}$
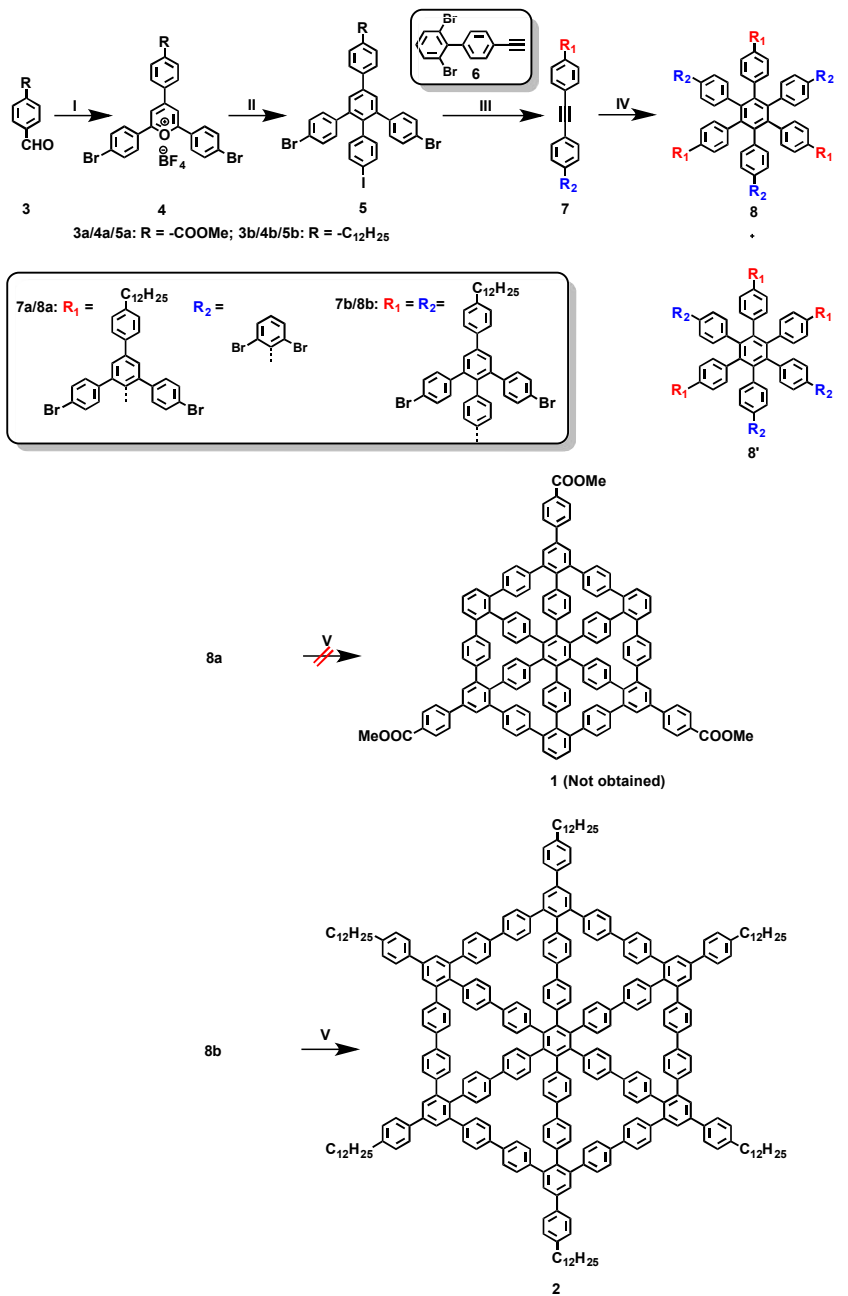

${ }^{\mathrm{a}}$ Reagents and conditions: (i) 4-bromoacetophenone, $\mathrm{BF}_{3} \cdot \mathrm{Et}_{2} \mathrm{O}$, $100{ }^{\circ} \mathrm{C}, 12 \mathrm{~h}$; 4a: 25\%; 4b: 46\%; (ii) sodium 4-iodophenacetate $\mathrm{Ac}_{2} \mathrm{O}, 150{ }^{\circ} \mathrm{C}, 12 \mathrm{~h}$; 5a: $47 \%$; 5b: 39\%; (iii) 7a: 6, $\mathrm{Pd}\left(\mathrm{PPh}_{3}\right)_{2} \mathrm{Cl}_{2}$, $\mathrm{Et}_{3} \mathrm{~N}$, THF, $12 \mathrm{~h}, \mathrm{rt}, 71 \%$; 7b: 1,2-bis(4-(4,4,5,5-tetramethyl1,3,2-dioxaborolan-2-yl)phenyl)acetylene, $\quad \mathrm{Pd}\left(\mathrm{PPh}_{3}\right)_{4}, \quad \mathrm{~K}_{2} \mathrm{CO}_{3}$, THF, methanol $/ \mathrm{H}_{2} \mathrm{O}, 12 \mathrm{~h}, 60{ }^{\circ} \mathrm{C}, 58 \%$; (iv) $\mathrm{Co}_{2}(\mathrm{CO})_{8}$, toluene, refluxing; 8a: 23\%; 8b: 34\%; (v) $\mathrm{Ni}(\mathrm{COD})_{2}$, COD, bipyridine, THF, $120{ }^{\circ} \mathrm{C}$, microwave reactor; $1: 0 \% ; 2$ : $58 \%$. THF: tetrahydrofuran. COD: 1,5-cyclooctadiene.

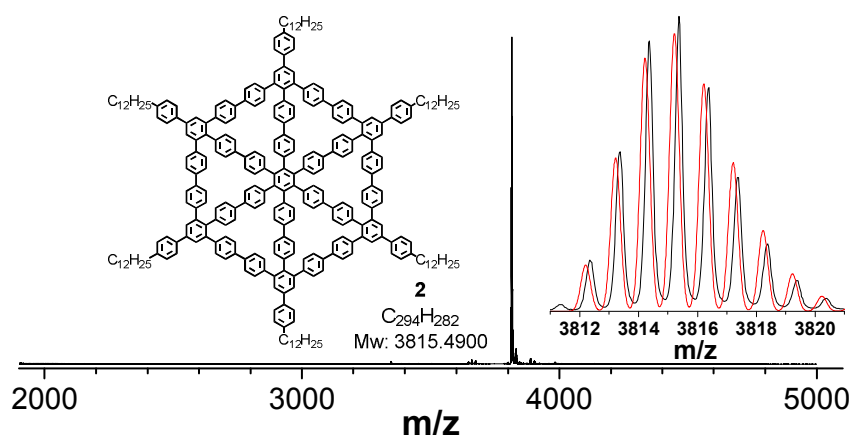

Figure 2. MALDI-TOF MS spectrum of 2. Inset: isotopic distribution (black) compared with mass spectrum simulated (red) for $\mathrm{C}_{294} \mathrm{H}_{282}$.

${ }^{1} \mathrm{H}$ NMR together with 2D COSY and NOESY spectra provided further structural proof for compound $\mathbf{2}$, where every aromatic 
proton signal could be unambiguously assigned (Figures 3, S9, and $\mathrm{S} 10)$. The ${ }^{1} \mathrm{H}$ NMR spectrum displayed that only the signals from $\mathrm{H}_{\mathrm{e}}, \mathrm{H}_{\mathrm{g}}$, and $\mathrm{H}_{\mathrm{h}}$ were slightly up-field shifted from 7.48, 7.23, and $7.20 \mathrm{ppm}$ to $7.42,7.15$, and $7.14 \mathrm{ppm}$, respectively, when the temperature was raised from 298 to $366 \mathrm{~K}$. This is presumably because these protons are pointing out of the plane at room temperature due to the steric repulsion, but have higher freedom of rotation at an elevated temperature, leading to a reduced deshielding effect from the adjacent phenylene ring. Furthermore, the diameter of $\mathbf{2}$ in tetrachloroethane could be estimated to be 3.89 $\mathrm{nm}$ based on the NMR diffusion-ordered spectroscopy (DOSY) measurement (Figure S11) with a calculated self-diffusion constant (D) of $7.06 \times 10^{-11} \mathrm{~m}^{2} \mathrm{~s}^{-1}$, which was comparable with the theoretical molecular size $(3.74 \mathrm{~nm})$ of the polyphenylene core of 2 calculated by the density functional theory (DFT) at the level of B3LYP/6-31G(d) (Figure S4).

The theoretically calculated geometry of 2 (DFT, B3LYP/6$31 \mathrm{G}(\mathrm{d})$ ) clearly showed that its polyphenylene backbone is confined into a two-dimensional plane, in contrast to threedimensional polyphenylene dendrimers. Six 'rim-like' biphenylylene units are supported by six 'spoke-like' biphenylylene segments and they are all tilted out of the plane (Figures S3 and S4). The UV-Vis absorption spectrum of 2 displays a slight blueshift of $\sim 10 \mathrm{~nm}$ compared to that of precursor $7 \mathbf{b}$, which is presumably due to a decrease in the effective conjugation length of $p$ oligophenylene units by the tilting (Figure S2a). Indeed, the absorption spectrum of $\mathbf{2}$ is similar to those of cyclic nonaphenylene derivatives reported by Iyoda et al., ${ }^{29}$ suggesting the interruption of the $\pi$-conjugation. On the other hand, the fluorescence spectra display a red shift and a larger Stokes shift for $2\left(\lambda_{\mathrm{fl}}=422 \mathrm{~nm}\right.$, with a shift of $125 \mathrm{~nm})$ compared to those of $\mathbf{8 b}\left(\lambda_{\mathrm{fl}}=393 \mathrm{~nm}\right.$, with a shift of $83 \mathrm{~nm}$ ) (Figure S2c), which suggests that the excited state of $\mathbf{2}$ has a more planarized structure than that of $\mathbf{8 b}$, with extended $\pi$-conjugation in contrast to their ground-state structures.

To confirm the shape-persistent nature of the wheel-like molecule, a self-assembled monolayer of $\mathbf{2}$ was characterized at submolecular resolution using STM at the 1-phenyloctane/highly oriented pyrolytic graphite (HOPG) interface at room temperature (Figure 4). Wheel-like molecule 2 formed a hexagonal 2D pattern on the substrate with unit cell parameters of $a=b=4.7 \pm 0.2 \mathrm{~nm}$ and $\alpha=60 \pm 3^{\circ}$. Figure $4 \mathrm{a}$ shows a high-resolution STM image of the monolayer where sub-molecular features within the aromatic part of the molecular spoked wheel are clearly visible. The conjugated polyphenylene cores appear as bright spoked wheels separated by darker regions wherein the peripheral dodecyl chains are adsorbed

A molecular model (Figure $4 \mathrm{~b}$ ) built using the experimentally obtained lattice parameters reveals that the dodecyl chains possibly interact with each other via van der Waals interactions. The model also shows that the region in between the dodecyl chains is largely empty, and thus it is possibly filled by mobile solvent molecules. The dimension of the polyphenylene core obtained from calibrated STM images (as indicated by the dashed line in Figure 4d: $2.4 \mathrm{~nm}$ ) matches closely with the one obtained from the theoretically calculated structure $(2.2 \mathrm{~nm})$. Furthermore, the STM contrast of the aromatic core matches closely with the anticipated structure of $\mathbf{2}$. Each bright feature consists of a hexagonal frame ('rim-like' biphenylylenes) filled with a star-shaped feature ('spoke-like' biphenylylenes) with a central dark blob. The 'spoke-like' biphenylylenes give rise to six adjacent pores as expected from the molecular structure (Figure $4 \mathrm{c}$ and $4 \mathrm{~d}$ ). The tilted biphenylylenes have presumably enhanced the selfassembly by multiple " $\mathrm{CH}-\pi$ " interactions with the graphite surface. The peripheral phenyl rings that form a part of the phenyl dodecyl substitution are also visualized (arrows in Figure 4a and $4 \mathrm{~b})$. Thus, the STM analysis not only proved the chemical struc- ture of the targeted compound $\mathbf{2}$, but also provided direct evidence for its shape-persistent conformation on a solid substrate, which was not accessible via conventional characterization methods.

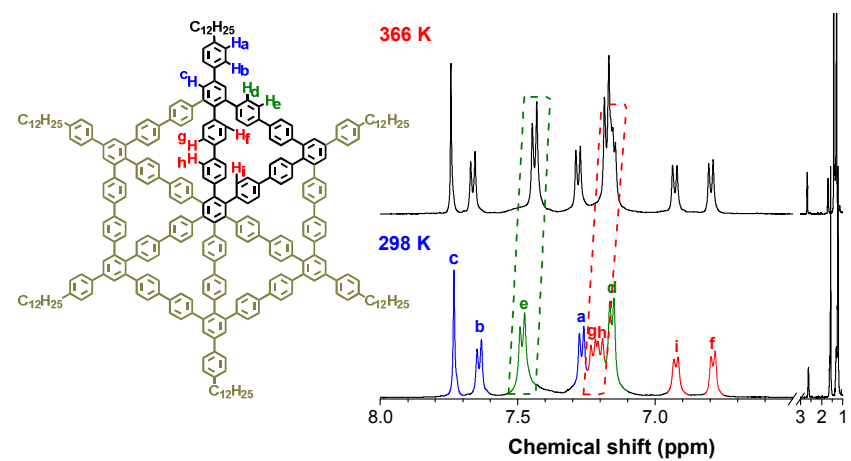

Figure 3. ${ }^{1} \mathrm{H}$ NMR spectrum of 2 in $\mathrm{C}_{2} \mathrm{D}_{2} \mathrm{Cl}_{4}$ at room temperature with the assignment of aromatic protons.

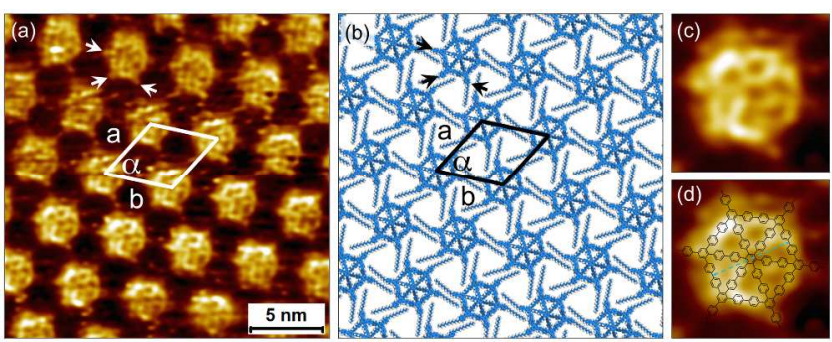

Figure 4. (a) High-resolution STM image of a self-assembled monolayer of 2 . The unit cell parameters are $\mathrm{a}=\mathrm{b}=4.7 \pm 0.2 \mathrm{~nm}$, and $\alpha=60 \pm 3.0^{\circ}$ (one molecule per unit cell). Tunneling current, $I_{\text {set }}=25 \mathrm{pA}$; Sample bias, $V_{\text {bias }}=-1.5 \mathrm{~V}$. (b) Molecular model of the self-assembled network of 2. (c) Digital zoom $(4.1 \mathrm{~nm} \times 4.1$ $\mathrm{nm}$ ) of the STM image provided in panel (a) showing the aromatic core of a single molecule of 2 . (d) Same image as in (c) but overlapped with the molecular structure of 2 .

In summary, we considered two 2D carbon architectures, graphenylene-1 and graphenylene-2, with hexagonal symmetry by replacing ethynyl groups of $\gamma$-graphyne and graphdiyne, respectively, with $p$-phenylene linkages, and synthesized a shapepersistent polyphenylene spoked wheel $\mathbf{2}$, corresponding to a subunit of graphenylene-2. With the assistance of the hexaphenylbenzene core as the cyclization template, the macrocyclic backbone of 2 was constructed via six-fold intramolecular nickelcatalyzed coupling with high yield. Remarkably, a submolecularresolution STM image could be obtained at the liquid/solid interface, clearly elucidating the shape-persistent "spoked wheel" structure of 2. Such molecular structure with six internal pores (approximately $4 \AA$ in diameter as measured both in models and STM images) can be highly interesting for studying supramolecular interactions with other guest molecules or ions, since they are expected to accommodate e.g. methyl groups or $\mathrm{Br}^{-}$and $\mathrm{I}^{-}$anions. These results open up a new avenue for designing and synthesizing a further variety of unprecedented $2 \mathrm{D}$ carbon structures and their subunits.

\section{ASSOCIATED CONTENT}

\section{Supporting Information}

Experimental details, cyclic voltammograms, NMR, UV-Vis absorption, fluorescence, and MALDI-TOF MS spectra, and additional STM images and molecular models. "This material is available free of charge via the Internet at http://pubs.acs.org." 


\section{AUTHOR INFORMATION}

\section{Corresponding Author}

*xinliang.feng@tu-dresden.de

*muellen@mpip-mainz.mpg.de

\section{Notes}

The authors declare no competing financial interest.

\section{ACKNOWLEDGMENT}

We are grateful for the financial support from the European Research Council grant on NANOGRAPH as well as under the European Union's Seventh Framework Programme (FP7/20072013)/ERC grant agreement no. 340324, the European Commission through the FET project UPGRADE (GA-309056) and Graphene Flagship (No. CNECT-ICT-604391), and DFG Priority Program SPP 1459.

\section{REFERENCES}

(1) Geim, A. K.; Novoselov, K. S. Nature Mater. 2007, 6, 183.

(2) Segawa, Y.; Ito, H.; Itami, K. Nat. Rev. Mater. 2016, 1, 15002.

(3) Pinzón, J. R.; Villalta-Cerdas, A.; Echegoyen, L. In Unimolecular and Supramolecular Electronics I: Chemistry and Physics Meet at MetalMolecule Interfaces; Metzger, M. R., Ed.; Springer Berlin Heidelberg: Berlin, Heidelberg, 2012, p 127.

(4) Jariwala, D.; Sangwan, V. K.; Lauhon, L. J.; Marks, T. J.; Hersam, M. C. Chem. Soc. Rev. 2013, 42, 2824.

(5) Novoselov, K. S.; Geim, A. K.; Morozov, S. V.; Jiang, D.; Zhang, Y.; Dubonos, S. V.; Grigorieva, I. V.; Firsov, A. A. Science 2004, 306, 666.

(6) Falcao, E. H. L.; Wudl, F. J. Chem. Technol. Biotechnol. 2007, 82, 524.

(7) Georgakilas, V.; Perman, J. A.; Tucek, J.; Zboril, R. Chem. Rev. 2015, $115,4744$.

(8) Zhang, S.; Zhou, J.; Wang, Q.; Chen, X.; Kawazoe, Y.; Jena, P. Proceedings of the National Academy of Sciences 2015, 112, 2372.

(9) Sharma, B. R.; Manjanath, A.; Singh, A. K. Sci. Rep. 2014, 4, 7164.
(10) Li, Y.; Xu, L.; Liu, H.; Li, Y. Chem. Soc. Rev. 2014, 43, 2572.

(11) Hirsch, A. Nature Mater. 2010, 9, 868.

(12) Diederich, F.; Rubin, Y. Angew. Chem. Int. Ed. Engl. 1992, 31, 1101.

(13) Diederich, F. Nature 1994, 369, 199.

(14) Baughman, R. H.; Eckhardt, H.; Kertesz, M. J. Chem. Phys. 1987, 87, 6687.

(15) Bieri, M.; Treier, M.; Cai, J.; Aitt-Mansour, K.; Ruffieux, P.; Groning, O.; Groning, P.; Kastler, M.; Rieger, R.; Feng, X.; Müllen, K.; Fasel, R. Chem. Commun. 2009, 6919.

(16) Eichhorn, J.; Nieckarz, D.; Ochs, O.; Samanta, D.; Schmittel, M.; Szabelski, P. J.; Lackinger, M. ACS Nano 2014, 8, 7880.

(17) Klappenberger, F.; Zhang, Y.-Q.; Björk, J.; Klyatskaya, S.; Ruben, M.; Barth, J. V. Acc. Chem. Res. 2015, 48, 2140.

(18) Li, Q.; Yang, B.; Lin, H.; Aghdassi, N.; Miao, K.; Zhang, J.; Zhang, H.; Li, Y.; Duhm, S.; Fan, J.; Chi, L. J Am Chem Soc 2016, 138, 2809.

(19) Malko, D.; Neiss, C.; Viñes, F.; Görling, A. Phys. Rev. Lett. 2012, $108,086804$.

(20) Zhou, J.; Gao, X.; Liu, R.; Xie, Z.; Yang, J.; Zhang, S.; Zhang, G.; Liu, H.; Li, Y.; Zhang, J.; Liu, Z. J Am Chem Soc 2015, 137, 7596.

(21) Bhaskar, A.; Guda, R.; Haley, M. M.; Goodson J Am Chem Soc 2006, $128,13972$.

(22) Haley, M. M.; Brand, S. C.; Pak, J. J. Angew. Chem. Int. Ed. Engl. 1997, 36, 836.

(23) Iyoda, M.; Yamakawa, J.; Rahman, M. J. Angew. Chem. Int. Ed. 2011, 50, 10522 .

(24) H. F. Bunz, U.; Rubin, Y.; Tobe, Y. Chem. Soc. Rev. 1999, $28,107$. (25) Tahara, K.; Yoshimura, T.; Sonoda, M.; Tobe, Y.; Williams, R. V. J. Org. Chem. 2007, 72, 1437.

(26) Baughman, R. H.; Cui, C. Synth. Met. 1993, 55, 315.

(27) May, R.; Jester, S.-S.; Höger, S. J Am Chem Soc 2014, 136, 16732. (28) Mössinger, D.; Hornung, J.; Lei, S.; De Feyter, S.; Höger, S. Angew. Chem. Int. Ed. 2007, 46, 6802.

(29) Rahman, M. J.; Yamakawa. J.; Matsumoto, A.; Enozawa, H.; Nishinaga, T.; Kamada, K.; Iyoda, M. J. Org. Chem. 2008, 73, 5542. 


\section{Page 5 of 5}

Journal of the American Chemical Society

Table of Contents

2

4

5

6

7

8

9

10

11

12

13

14

15

16

17

18

19

20

21

22

23

24

25

26

27

28

29

30

31

32

33

34

35

36

37

38

39

40

41

42

43

44

45

46

47

48

49

50

51

52

53

54

55

56

57

58

59

60
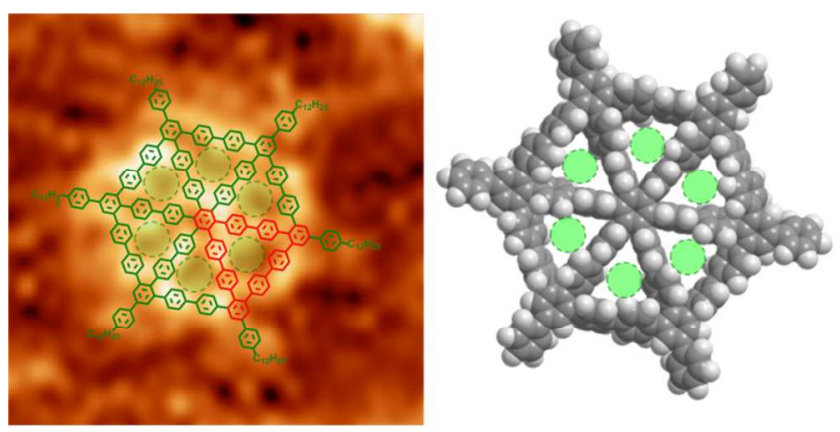

Shape-persistent macrocycle of $s p^{2}-$ hybridized carbons 